\title{
PENDAMPINGAN KEMANDIRIAN TPA AZ-ZAHRA BERBASIS PEMASARAN SOSIAL
}

\author{
Ike Arisanti $^{* 1}$, Novitasari Agus Saputri ${ }^{2}$ \\ ${ }^{1,2}$ Fakultas Ekonomi dan Bisnis, Universitas Muhammadiyah Malang \\ Jl. Raya Tlogomas No.246 Malang, Jawa Timur Indonesia \\ *E-mail : ikearisanti@umm.ac.id
}

\begin{abstract}
Tempat Pengasuhan Anak (TPA) Az-Zahra is a childcare center that was established in 2011 under the leadership of the Aisyiyah area of Malang. Lots of Child Care Centers in Malang are able to offer competent facilities, facilities and infrastructure as well as managers. Servants have solutive suggestions related to marketing that can be done by partners, namely by creating websites and marketing through social media. Besides social marketing can also be done by holding parenting activities that also invite potential customers who are around the Az-Zahra landfill. This program is carried out jointly with the hope that the results generated from this program can be directly measured and evaluated by partners and service as a basis for the success of the predetermined achievements. In addition, the evaluation results are also used as a basis for assistance in subsequent programs.
\end{abstract}

Keywords-Parenting, Self Assistance, Social-based Marketing, TPA Az-Zahra

\begin{abstract}
Abstrak
TPA Az-Zahra merupakan tempat pengasuhan anak yang berdiri pada tahun 2011 di bawah pimpinan daerah Aisyiyah Kota Malang. Lokasi di Jalan Tlogo Al-Kautsar No. 47 yang dikelola oleh tiga orang anggota Aisiyah Kota Malang. Banyak sekali Tempat Penitipan Anak di Kota Malang yang mampu memberikan penawaran fasilitas, sarana dan prasaran serta pengelola yang kompeten. Selain itu pemasaran yang bersifat sosial juga dapat dilakukan dengan cara mengadakan kegiatan parenting yang turut mengundang calon konsumen yang berada disekitar TPA Az-Zahra.. Program ini dilaksankaan secara bersama- sama dengan harapan capaian yang dihasilkan dari program ini dapat langsung diukur dan dievaluasi oleh mitra maupun pengabdi sebagai dasar keberhasilan capaian yang telah ditentukan. Selain itu hasil evaluasi juga dijadikan dasar untuk melakukan pendampingan di program- program selanjutnya. Kegiatan parenting memiliki tujuan utama untuk mensosialisasikan pentingnya orang tua dalam mengasuh dan mendidik anak. Akan tetapi selain peranan penting tersebut ada tujuan khusus TPA Az-Zahra mengundang masyarakat untuk berkunjung. Hal ini kemudian direpresentasikan sebagai alat untuk mengenalkan TPA AzZahra kepada masyarakat sekitar.
\end{abstract}

Kata Kunci-Parenting, Pendampingan Kemandirian, Pemasaran berbasis sosial, TPA Az-Zahra,

\section{PENDAHULUAN}

TPA Az-Zahra merupakan tempat pengasuhan anak yang berdiri pada tahun 2011 di bawah pimpinan daerah Aisyiyah Kota Malang. Lokasi di Jalan Tlogo Al-Kautsar No. 47. Pengelolaan dilakukan oleh Ibu Emy Widyawati sebagai penanggung jawab dibawah pimpinan daerah Aisyiyah. Ibu Emy dibantu oleh 3 orang rekannya yang menjabat sebagai kepala sekolah dan pengasuh. Pengelolaan TPA ini dilaksanakan berdasarkan prinsip- prinsip dan nilai keislaman. Hal ini berkaitan langsung dengan tujuan dan visi misi TPA Az-Zahra.

Tempat pengasuhan anak az-zahra memiliki tujuan untuk menjadi tempat pengasuhan anak yang islami dengan target jangka panajang kedepannya ingin memperluas amal usaha mendirikan taman kanak-kanak. Adapun untuk menunjang terpenuhinya target tersebut semua guru pengasuh dibekali ilmu keislaman untuk mengikuti baitul arqam yang diselenggarakan oleh pimpinan Aisyiyah 
daerah Kota Malang.Target yang jangka pendek yang saat ini sedang dalam proses adalah masalah legalitas, dari sejak pertama berdiri dan menerima siswa baru pada 1 oktober 2011 sampai sekarang TPA Az-zahra belum memiliki izin secara legal.

Aktivitas TPA az-zahra mengajarkan anak untuk menjadi anak yang mandiri akan tetapi tetap terkontrol, misalkan saja pengasuh mengajarkan kepada anak bagaimana tata cara makan secara mandiri dengan pendampingan pengasuh, mengikat tali sepatu, memakai baju sendiri, pergi ke kamar mandi sendiri, dan lain - lain. Selain itu di TPA anak-anak dikenalkan dengan ilmu agama dengan diajari ibadah baik sholat maupun membaca Iqro, TPA juga memiliki program pro- ASI yang maksudnya orang tua yang menitipkan anaknya di TPA diutamakan untuk memberikan ASI eklusif kepada anaknya, orang tua diperkenankan untuk datang menyusui anaknya ketika jam istirahat kerja.

Kedepan TPA Az-zahra juga memiliki rencana untuk menyediakan makanan secara langsung kepada para anak hal ini bertujuan agar makanan yang dikonsumsi anak adalah makanan yang bergizi mengingat semua orang tua yang menitipkan anak di TPA adalah para pekerja, biasanya para pekerja cenderung memberikan makanan bubur instan untuk anaknya karena dianggap lebih praktis. Untuk itu kedepannya TPA akan menyediakan makanan yang higienis dan bergizi agar para orang tua tidak perlu repot untuk membawakan makanan kepada anaknya di penitipan.

Sarana dan prasarana yang ada di TPA Az-Zahra kurang representatif sebagai lembaga pendidikan anak, misalkan saja sarana untuk penghangat Asi yang masih sederhana yaitu menggunakan air hangat sedangkan sesuai dengan salah satu program kerja TPA yaitu Pro-Asi seharusnya memiliki alat penghangat asi yang lebih higienis dan praktis. Sarana yang tersedia adalah kasur, lemari, dan mainan anak.

Potensi untuk menarik minat konsumen dari Tempat Penitipan Anak ini sesungguhnya sangat tinggi, hal ini didukung oleh lokasi yang strategis yakni ditengah perkampungan serta dekat dengan lembaga pendidikan yaitu Universitas Muhammadiyah Malang. Namun, menurut pengelola, murid yang ada di TPA Az-Zahra sampai hari ini hanya berjumlah 4 anak, padahal ketika awal pendirian kami menerima sampai 14 Murid tetapi sekarang mengalami penurunan yang sangat drastis. Menurut pengelola kondisi ini disebabkan karena kurangnya publikasi dan pengenalan TPA Az-Zahra kepada masyarakat. Selain itu pengelola juga menyampaikan bahwa kualitas pengelolaa dan sarana prasarana yang kurang menjadikan masyarakat enggan untuk menitipkan anak mereka ke tempat tersebut.

Konsumen atau masyarakat memiliki idealisme yang tinggi mengenai kualitas tempat penitipan anak. Hal disebabkan oleh kebutuhan konsumen akan kenyamanan dan kebutuhan perlindungan terhadap anak- anak mereka ketika diasuh oleh pengasuh di penitipan anak, hal ini berdasarkan hasil wawancara yang dilakukan kepada Ibu Aviani Widyastuti salah satu dosen muda Universitas Muhammadiyah Malang. Pengusul mencari informasi kebutuhan konsumen terhadap beberapa karyawan dan dosen UMM karena UMM merupakan salah satu pangsa pasar yang dibidik oleh TPA Az-Zahra karena kedekatan lokasi dengan kampus UMM.

Banyak sekali Tempat Penitipan Anak di Kota Malang yang mampu memberikan penawaran fasilitas, sarana dan prasaran serta pengelola yang kompeten. Mereka gencar melakukan promosi untuk menarik minat konsumen. Misalkan saja TPA Children Center BSS Universitas Brawijaya Malang. Mereka memiliki pangsa pasar khusus dosen dan karyawan yang memiliki balita. Akan tetapi mereka juga tidak menutup kesempatan bagi masyarakat diluar Universitas Brawijaya untuk menitipkan anak mereka ke TPA BSS. Jika dilihat dari lokasinya memang TPA BSS sangat strategis, karena berada dekat dengan kampus UB sehingga mereka mudah mencari konsumen. Akan tetapi mereka tidak diam begitu saja, banyak event yang diselenggarakan secara rutin dengan tujuan untuk menarik masyarakat luas salah satunya adalah dengan promosi. Promosi yang dilakukan tidak hanya secara langsung namun juga tidak secara langsung. Promosi secara langsung misalkan mengedarkan pamflet kepada masyarakat tentang keberadaan TPA BSS. Promosi tidak secara langsung dapat dilakukan dengan menggunakan website, kegiatan sosial yang melibatkan orang tua murid serta pemanfaataan media sosial yang dapat dijangkau oleh masyarakat misalkan FB, Instagram, Whatshap dll.

Adapun kondisi TPA Az-zahra yang sudah dijelaskan diatas jika dibandingkan dengan idealisme konsumen serta kondisi TPA yang ada disekitar TPA Az- Zahra, maka TPA ini sesungguhnya masih jauh dari kata berkembang. Khususnya jika ditinjau dari segi pemasaran, jika dibandingkan dengan TPA lainya maka TPA Az-Zahra intensitas pemasaranya sangat kurang. Hal 
ini tentunya berimbas kepada penilaian masyarakat sekitar terhadap TPA tersebut. Masyarakat kurang yakin menitipkan anak mereka karena ketidakpahaman fasilitas dan keunggulan yang diberikan oleh TPA Az-Zahra.

Kondisi di atas menjadi dasar pengabdi dalam memberikan saran dan solusi atas permasalahan yang dialami oleh TPA Az-Zahra khususnya dalam hal pemasaran. Tujuan pemasaran yang utama menurut Kotler adalah untuk memperkenalkan produk yang dimiliki agar dikenal oleh masyarakat sehingga masyarakat tertarik untuk menggunakan produk kita baik barang maupun jasa. Hal ini dapat dilakukan dengan cara menganalisis bauran pemasaran yang ada. Bauran pemasaran merupakan kumpulan alat pemasaran taktis yang terkendali yang dipadukan oleh perusahaan untuk menghasilkan respon yang diinginkan.; Kotler dan G.Amstrong menyebutkan bauran pemasaran ada 4 jenis yaitu product, price, promotion dan place (Kotler dan G. Amstrong, 2008 : 62). Adapun dari keempat landasan tersebut dapat diimplementasikan secara langsung. Akan tetapi pengusul masih mempertimbangkan dari keempatnya yang mana yang memiliki skala prioritas yang relatif lebih tinggi. Pemasaran atau promotion merupakan jenis bauran pemasaran yang tepat jika dihubungkan dengan kondisi TPA Az- Zahra saat ini.

Ibu Emy Widyawati sebagai penanggung jawab TPA Az-Zahra mmengungkapkan:

"Murid yang ada di TPA Az-Zahra mengalami penurunan murid yang sangat drastis dari awalnya 14 anak menjadi 4 anak, kami juga mengurangi jumlah pengasuh yang ada di TPA. Hal ini disebabkan karena kami kurang pemasaran, pemasaran yang selama ini dilakukan hanya melalui mulut ke mulut sehingga pangsa pasar kita masih sangat terbatas, untuk itu kami perlu memperkenalkan lebih luas terkait keberadaan TPA"

Pengabdi memberikan saran penyelesaian masalah yang dihadapi oleh TPA Az-Zahra, saran tersebut adalah melakukan pemasaran dengan pendekatan sosial. Pemsaran dengan pendekatan sosial misalkan saja adalah dengan cara mensosialisasikan TPA Az-Zahra kepada masyarakat sekitar melalui kegiatan parenting. Kagiatan parenting memiliki tujuan utama untuk mensosialisasikan pentingnya orang tua dalam mengasuh dan mendidik anak. Akan tetapi selain peranan penting tersebut ada tujuan khusus TPA Az-Zahra mengundang masyarakat untuk berkunjung. Hal ini kemudian direpresentasikan sebagai alat untuk mengenalkan TPA Az-Zahra kepada masyarakat sekitar. Selain itu, momen kegiatan parenting juga bertujuan untuk memberikan pemahaman kepada masyarakat khsususnya orang tua bahwa mengasuh dan mendidik anak diperlukan ilmu dan TPA Az-Zahra mampu memenuhi kebutuhan tersebut karena potensi keilmuan pengelola yang mumpuni. Selain itu dalam kegiatan parenting sekaligus digunakan untuk memberikan penguatansumber daya manusia di TPA.

Program keayahbundaan (parenting) yang menjadi salah satu program dalam penguatan kehidupan keluarga dan masyarakat Indonesia, memberikan salah satu penguatan dalam kehidupan masyarakat, terutama perkembangan anak usia dini, metode pengasuhan dan pola komunikasi yang dijalankan oleh sebagian besar masyarakat (Akhyadi \& Mulyono, 2018). Adapun saran lain yang diajukan pengabdi sebagai solusi pemecahan masalah TPA Az-Zahra adalah pemsaran dengan penedekatan sosial melalui website. Era 2019 merupakan era melek teknologi, maka harapan pengusul dengan membuatkan website serta cara pengelolaanya tersebut TPA Az-Zahra lebih dikenal oleh masyarakat luas.

Optimalisasi tumbuh kembang AUD sangat penting karena membantu meletakkan dasar ke arah perkembangan sikap, perilaku, pengetahuan, keterampilan dan daya cipta, yang ia perlukan untuk menyesuaikan diri dengan lingkungan dan untuk pertumbuhan serta perkembangan selanjutnya (Nursahidin \& Muhtarulloh, 2017).

\section{METODE}

Masalah yang dihadapi mitra adalah kurangnya strategi pemasaran sehingga mitra kurang mendapatkan respos yang positif meskipun ada banyak peluang untuk menjadi konsumen mitra. Maka dari itu perlu adanya solusi untuk memecahkan masalah tersebut. Solusi pemecahan masalah yang ditawarkan dalam Iptek bagi Masyarakat melalui beberapa pendekatan, hal ini diharapkan mampu mengatasi beberapa masalah yang dialamai oleh mitra. Hal ini dapat dilakukan tentunya harus dengan adanya kerjasama antara pengabdi dan mitra yang baik. Untuk pemecahan masalah mitra solusi yang ditawarkan menggunakan pendekatan- pendekatan antara lain: 
a. Pendekatan Model Participatory Tecnology Development yang memanfaatkan teknologi tepat guna yang berbasis pada ilmu pengetahuan.

b. Model Community development yaitu pendekatan yang melibatkan mitra secara langsung sebagai obyek dan subyek dalam pelaksanaan kegiatan pengabdian kepada masyarakat

c. Edukatif yang pendekatan sosialisasi, pelatihan dan pendampingan sebagai sarana transfer ilmu pengetahuan dan pendidikan untuk pemberdayaan masyarakat.

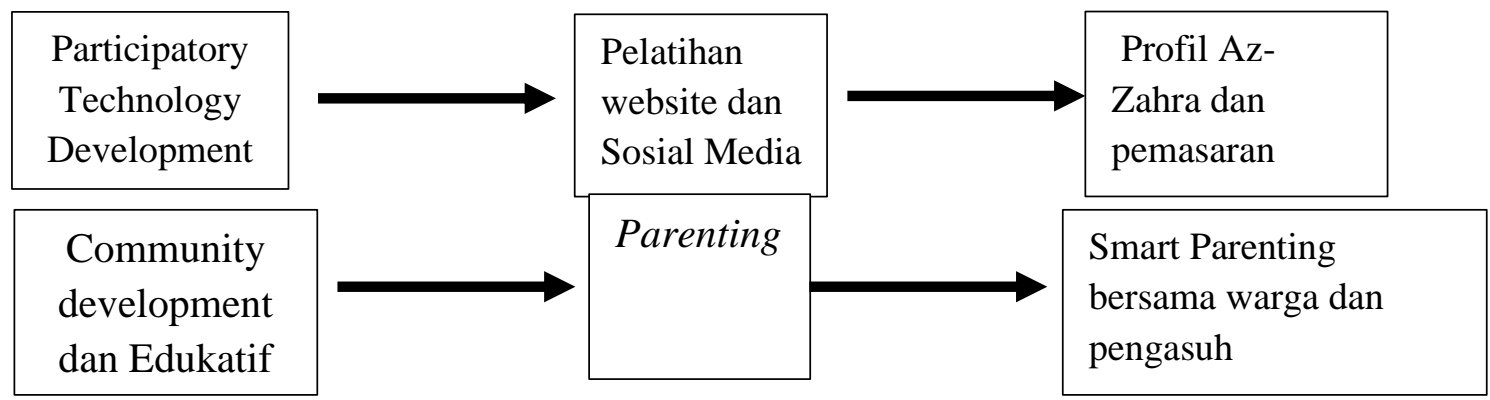

Gambar 1. Alur Solusi Pmecahan Masalah

Ketiga pendekatan di atas dapat dilaksanakan secara bersama- sama untuk menyelesaikan masalah yang dihadapi oleh mitra. Misalkan saja pendekatan model Participatory Tecnology Development yang memanfaatkan teknologi tepat guna yang berbasis pada ilmu pengetahuan pengusul dapat menyelesaikan masalah berdasarkan teori yang dikemukakan oleh Kotler dan G. Amstrong tentang bauran pemasaran, dimana bauran pemasaran teridiri dari 4P yaitu product, price, promotion dan place (Kotler dan G. Amstrong, 2008 : 62).

Berdasarkan gambar diatas,pengabdi akan memulai kegiatan IbM dari analisis masalah yang dihadapi mitra. Dari masalah yang dihadapi mitra pengusul akan menawarkan solusi dari masalahmasalah yang dihadapi oleh mitra. Mitra memiliki partisipasi aktif dalam kegiatan Iptek bagi Masyarakat. Salah satunya adalah berkoordinasi dengan pengabdi terkait masalah mitra yang dihadapi oleh mitra. Mitra memahami apa yang dibutuhkan atau permasalahan yang muncul dalam organisasinya sehingga koordinasi sangat penting dilakukan. Selain itu mitra juga memiliki partisipasi aktif dalam memberikan solusi atas masalah yang dihadapi. Hal ini penting dilakukan karena pada saat pengabdi mengajukan solusi atas masalah yang dihadapi oleh mitra maka mitra harus memahami terlebih dahulu solusi yang diajukan oleh pengusul. Hal ini dikarenakan berkaitan dengan kemampuan mitra dalam melaksanakan serta mengaplikasikan solusi yang telah ditawarkan oleh pengabdi. Selain itu mitra juga menyediakan tempat jika pengusul membutuhkan koordinasi langsung dengan mitra.

Adanya pelatihan tentang pengasuhan ramah anak diharapkan setiap pengasuh atau pendidik TPA di lembaga mitra menjadi mengetahui dan memahami pentingnya pengasuhan ramah anak dan bahayanya pengasuhan yang diwarnai dengan kekerasan, sehingga terbiasa untuk melaksanakan pengasuhan ramah anak, mengasuh dan membibing anak dengan tanpa kekerasan dan diskriminasi (Wahyuni, Desyanty, \& Redjeki, 2018). Selain itu adanya kegiatan parenting akan digunakan untuk saran memperkenalkan TPA kepada masyarakat.

Tabel 1. Evaluasi Kinerja

\begin{tabular}{clcc}
\hline \multirow{2}{*}{ Luaran } & \multicolumn{3}{c}{ Indikator Kinerja } \\
\cline { 2 - 4 } & Sebelum PKM & Target Akhir & Capaian Saat Ini \\
\hline Website & Tidak Ada & Ada & Ada \\
\hline Parenting & Tidak Ada & Ada & Ada \\
\hline
\end{tabular}

Pada tabel di atas dapat diketahui bahwa indikator kinerja pengabdi dapat diukur melalui perbandingan antara sebelum kegiatan pengabdian kepada masyarakat dibandingkan dengan capaian saat ini serta akan dbandingkan kembali dengan target akhir dari pelaksanaan pengabdian masyarakat. Hasil akhir dari penilaian atau evaluasi kinerja saat ini dapat diketahui bahwa semua luaran yang sudah direncanakan di awal kegiatan semua mencapai target target. 


\section{HASIL DAN PEMBAHASAN}

Salah satu contoh pengabdian kepada masyarakat yang dihubungkan dengan lembaga Tempat Pengasuhan Anak adalah dengan memberikan pengetahuan tentang arti penting mendidik anak di usia emas melalui acara seminar pareting (Frinza \& Meidiana, 2019). Dalam implementasinya, kegiatan ini bekerjasama dengan dosen Fakultas Psikologi sebagai pemateri prenting dalam kegiatan seminar parenting yang diselenggarakan di TPA Az-Zahra. Kegiatan ini diawali dengan rapat koordinasi dengan penganggung jawab TPA Az-Zahra. Pada rapat koordinasi tersebut tim pelaksana menganalisis masalah apa saja yang paling dominan di TPA Az-Zahra, masalah yang paling dominan dihadapi adalah penurunan jumlah siswa TPA Az-Zahra yang merupakan imbas dari kurangnya pemasaran yang dilakukan oleh pihak TPA Az Zahra. Dari hasil analisis masalah tersebut kemudian tim pelaksana menawarkan solusi.

Solusi yang kami lakukan terhadap masalah pemasaran tersebut adalah melakukan pendampingan dalam pembuatan dan pengelolaan website dan melakukan pemasaran berbasis sosial dengan membuat seminar parenting yang mengundang para konsumen potensial untuk hadir dalam seminar tersebut sekaligus memasarkan TPA Az-Zahra.

Seminar parenting kami laksanakan pada tanggal 15 Agustus 2019 dengan pemateri Putri Saraswati, S.Psi., M.Psi Dosen Fakultas Psikologi Universitas Muhammadiyah Malang sebagai pemateri. Kami juga mengundang dosen dan karyawan Universitas Muhammadiyah Malang beserta para guru dan orang tua wali TPA Az-zahra sebagai peserta. Pada acara seminar parenting ini ibu Emi Widyastuti sebagai penanggung jawab TPA Az-Zahra juga berkesempatan untuk memasarkan secara langsung TPA Az-Zahra kepada para peserta seminar. Pemasaran langsung memiliki manfaat diantaranya dapat menjangkau calon konsumen potensial disaat yang tepat, dapat mengukur tanggapan konsumen atas promosi yang dilakukan.

Sehingga pelatihan ini bermanfaat bagi orangtua untuk meningkatkan kemampuan kognitif dan psikososial anak. Ragam cara yang dapat dilakukan oleh orangtua sambil bermain dengan cara yang menyenangkan. Manfaat lain yang didapatkan orangtua dalam pelatihan itu yaitu orangtua dapat memanfaatkan barang bekas yang ada dirumah untuk bisa dilakukan bersama anak (Bustan, Nurfadilah, \& Fitria, 2017). Sehingga dapat kita ambil kesimpulan bahwa pendidikan anak pada usia dini merupakan sesuatu hal yang penting. Sejalan dengan hal tersebut, kini Kementerian Pendidikan dan Kebudayaan menggulirkan kebijakan strategis yaitu percepatan dan perluasan layanan Pendidikan Anak Usia Dini (PAUD) (PUSPITA, 2013).

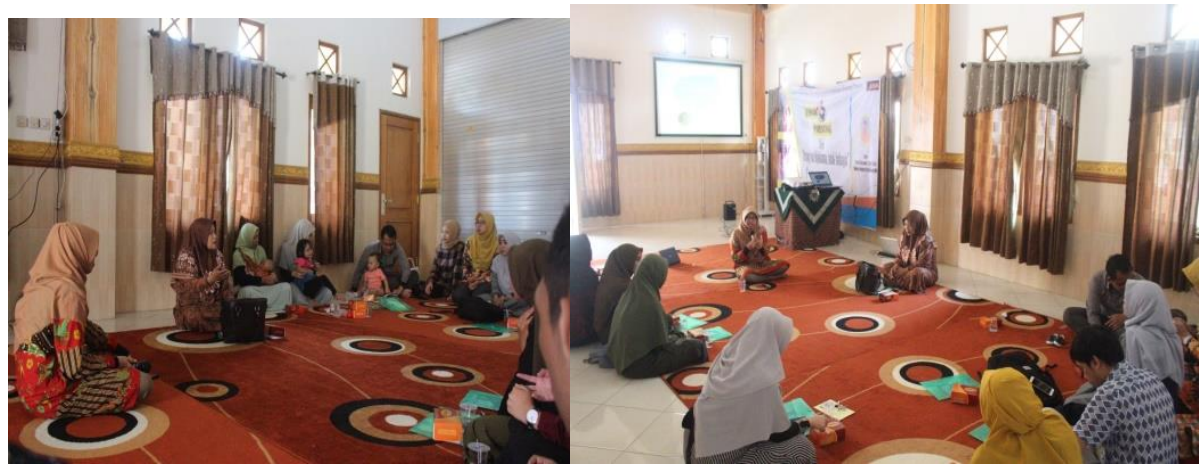

Gambar 1. Foto Pelaksanaan Seminar Parenting

Selain menyelenggarakan seminar parenting, tim pelaksana juga menyelenggarakan pelatihan dan pendampingan mebuatan website. Webstie merupakan salah satu media online yang memiliki dampak yang luas dalam pemasaran diantaranya dapat menjangkau terget pasar yang lebih luas, mudah diakses, sarana untuk menampilkan profil usaha dan portofolio jasa dan dapat selalu terhubung dengan pelanggan. 


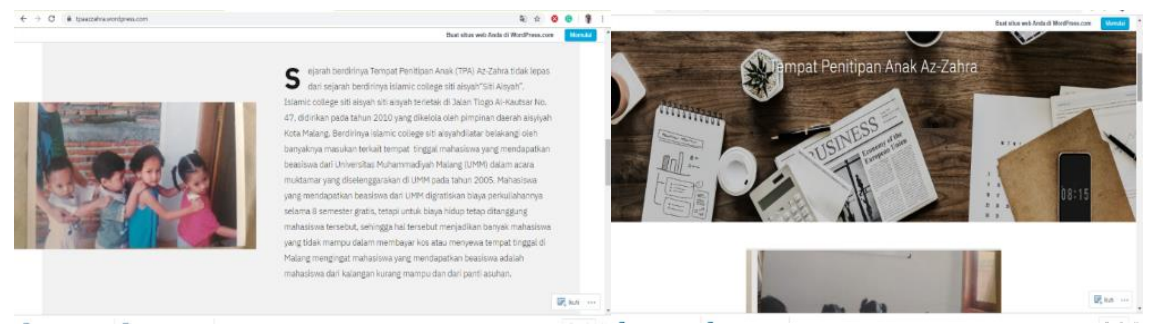

Gambar 2. Website TPA Az-Zahra

Secara ringkas, capaian kinerja yang telah dilaksanakan oleh pengabdi dapat dilihat dalam tabel di bawah ini:

\begin{tabular}{llccl}
\hline \multirow{2}{*}{ Luaran } & \multicolumn{3}{c}{ Indikator Kinerja } & Keterangan \\
\cline { 2 - 5 } & $\begin{array}{l}\text { Sebelum } \\
\text { PKM }\end{array}$ & $\begin{array}{l}\text { Target } \\
\text { Akhir }\end{array}$ & \multicolumn{2}{c}{ Capaian Saat } \\
Ini & \\
\hline Website & Tidak Ada & Ada & Ada & Gambar 2 \\
\hline Parenting & Tidak Ada & Ada & Ada & Gambar 1 \\
\hline
\end{tabular}

\section{KESIMPULAN}

Kesimpulan dari kegiatan pengabdian masyarakat ini adalah mitra sangat terbantu dengan adanya pengembangan strategi promosi dengan pendekatan sosial. Terbukti dengan adanya suport oleh mitra kepada pengabdi dalam setiap penyelenggaraan kegiatan, yaitu kegiatan pembuatan website dan juga kegiatan parenting. Harapan pengabdi bersama mitra dengan adanya kedua kegiatan tersebut TPA Az-Zahra semakin dikenal masyarakat dan masyarakat tertarik untuk menitipkan anak mereka kepada TPA Az-Zahra.

\section{SARAN}

Saran yang diberikan kepada mitra setelah kegiatan pengabdian masyarakat ini dilakukan adalah meningkatkan kualitas maupun kuantitas sumber daya manusia, yakni pengasuh yang ada di TPA Az-Zahra. Jumlah pengasuh yang masih terbatas sehingga jika anak asuh bertambah setalah kegiatan pengabdian melalui pemasaran ini, maka sangat diperlukan adanya rekruitmen khususnya pengasuh TPA Az-Zahra.

\section{DAFTAR PUSTAKA}

[1] Akhyadi, A. S., \& Mulyono, D. 2018. Program Parenting Dalam Meningkatkan Kualitas Pendidikan Keluarga. Abdimas Siliwangi: Jurnal Pengabdian Kepada Masyarakat, 1(1), 1-8.

[2] Adhimsyah, Lutfi. 2017. Analisis Pengaruh Bauran Pemasaran Dan Pelayanan Terhadap Keputusan Pembelian Pada Perumahan Green Tegal Gede Residence. Prosiding Seminar Nasional Dan Call For Paper Ekonomi Dan Bisnis (SNAPER- EBIS 2017) - Jember, 27- 28 Oktober 2017 (Hal 477 - 485) ISBN :978- 602 - 5617 - 01 - 0

[3] Bustan, R., Nurfadilah, N., \& Fitria, N. 2017. Pelatihan Optimalisai Tumbuh Kembang Anak Pada Orangtua Anak Usia Dini. Jurnal Al-Azhar Indonesia Seri Humaniora, 3(3), 274-282.

[4] Frinza, F., \& Meidiana, M. 2019. Integrasi Kewirausahaan Melalui Pendirian Lembaga Paud Sebagai Salah Satu Pengabdian Kepada Masyarakat. Dipresentasikan Pada Prosiding Seminar Nasional Program Pascasarjana Universitas Pgri Palembang.

[5] Kotler, Philip, Armstrong, G., Brown, L., And Adam, S. 2006. Marketing, $7^{\text {th }}$ Ed. Pearson Education Australia: Prentice Hall

[6] Kotlerp, G Amstrong. 2008. Prinsip Prinsip Pemasaran. Edisi Kedua Belas Jakarta: Penerbit Erlangga.

[7] Kotler, Philip \& Kevin Lane Keller. 2009. Marketing Management. Twelfth Edition. New Jersey: Pearson 
[8] Nursahidin, N., \& Muhtarulloh, F. 2017. Pengabdian Kepada Masyarakat Pemberdayaan Aparatur Desa Dalam Meningkatkan Kesadaran Masyarakat Terhadap Urgensi Paud (Ra) Serta Kelembagaan Paud Di Desa Cikidang Kecamatan Bantarujeg Kabupaten Majalengka. Jurnal Abdi: Media Pengabdian Kepada Masyarakat, 3(1), 1-5.

[9] Puspita, R. N. 2013. Perbedaan Tingkat Kemandirian Anak Usia Prasekolah (3-6 Tahun) Yang Dititipkan Di Taman Penitipan Anak Dan Yang Diasuh Oleh Orang Tuanya Sendiri.

[10] Wahyuni, S., Desyanty, E. S., \& Redjeki, E. S. 2018. Peningkatan Kompetensi Pengasuh Melalui Pelatihan Pengasuhan Ramah Anak Pada Taman Penitipan Anak. Abdimas Pedagogi: Jurnal Ilmiah Pengabdian Kepada Masyarakat, 1(2), 193-204. 